Article

\title{
Surface Plasmon Resonance Based Biosensors for Exploring the Influence of Alkaloids on Aggregation of Amyloid- $\beta$ Peptide
}

\section{Bartlomiej Emil Kraziński, Jerzy Radecki and Hanna Radecka *}

Institute of Animal Reproduction and Food Research of Polish Academy of Sciences, Tuwima 10 Street, 10-747 Olsztyn, Poland; E-Mails: b.krazinski@pan.olsztyn.pl (B.E.K.); j.radecki@ pan.olsztyn.pl (J.R.)

* Author to whom correspondence should be addressed; E-Mail: hanna.radecka@ pan.olsztyn.pl; Tel.: +4889-523-4636; Fax: +4889-524-0124.

Received: 16 February 2011; in revised form: 16 March 2011 / Accepted: 28 March 2011 /

Published: 6 April 2011

\begin{abstract}
The main objective of the presented study was the development of a simple analytical tool for exploring the influence of naturally occurring compounds on the aggregation of amyloid- $\beta$ peptide $\left(A \beta_{40}\right)$ in order to find potential anti-neurodegenerative drugs. The gold discs used for surface plasmon resonance (SPR) measurements were modified with thioaliphatic acid. The surface functionalized with carboxylic groups was used for covalent attaching of $A \beta_{40}$ probe by creation of amide bonds in the presence of EDC/NHS. The modified SPR gold discs were used for exploring the $A \beta_{40}$ aggregation process in the presence of selected alkaloids: arecoline hydrobromide, pseudopelletierine hydrochloride, trigonelline hydrochloride and $\alpha$-lobeline hydrochloride. The obtained results were discussed with other parameters which govern the phenomenon studied such as lipophilicity/ hydrophilicy and $\mathrm{A} \beta_{40}$-alkaloid association constants.
\end{abstract}

Keywords: amyloid- $\beta$ peptide; surface plasmon resonance; alkaloids; thioaliphatic acid monolayer

\section{Introduction}

Abnormal folding and aggregation of proteins characterizes many, if not all, neurodegenerative disorders such as Alzheimer's (AD), Parkinson's, Creutzfeldt-Jakob disease and large group of poliglutamine disorders including Huntington's disease [1]. Aggregation of Amyloid- $\beta$ peptide (A $\beta)$ 
from its soluble monomers into insoluble well-ordered amyloid fibrils has been assumed to be a key molecular hallmark in the pathology of Alzheimer's disease (AD) [2,3]. In a nucleation-dependent polymerization model $A \beta_{40}$ aggregation consists of two phases: thermodynamically unfavourable nuclei formation, followed by their spontaneous elongation and growth. Soluble $\alpha$-helical or random-coil structures can convert into $\beta$-sheet protofibrilar intermediates which act as a seed for amyloid formation and plaque precipitation [4,5]. Formation of soluble $\beta$-sheet oligomers has been reported to be essential for neurodegeneration processes and is suspected to play a principal role in the A $\beta$-mediated toxicity [6]. Thus targeting of $\alpha$-helical and random-coil structures' transition to $\beta$-sheeted species could provide AD prevention and treatment or retard the onset of disease. Among other modes of action, direct targeting $A \beta$ misfolding and aggregation phenomenon might be one of the most promising therapeutic methods against AD disease.

Numerous plant-derived molecules have been tested in vitro and in vivo but special attention has been reserved for the alkaloid nicotine and its derivatives, as they are well known to exert an influence on cognitive functions [7]. While it seems that first of all the multiple influence of nicotine on cholinergic transmission is responsible for its beneficial effects on AD patients [8-10], there are in vitro studies suggesting that this alkaloid can alter $A \beta$ amyloidogenesis directly [11-14]. The associations of aggregated $A \beta_{40}$ with nicotine and cotinine as well as the other pyridine- and piperdine-derived alkaloids were determined electrochemically $[15,16]$. Since A $\beta$ is a target molecule in many $\mathrm{AD}$ therapies, compounds revealing significant affinity towards this peptide could also serve as effective $A \beta$ oligomerization and neurotoxicity inhibitors and have to be taken into consideration as possible anti-AD drugs.

Surface plasmon resonance (SPR) spectroscopy has been successfully employed in studies concerning molecular interactions associated with different amyloidoses [17]. Various aspects of $A \beta$ oligomerization, fibril growth, dissociation as well as A $\beta$ binding to biomolecules were examined with SPR [18]. The in vitro anti-amyloidogenic activity of metal ions chelators, short peptides, antibody fragments and flavonoids has been tested utilizing SPR-based methods [19-23]. In most SPR-based biosensors applied for study of $\mathrm{A} \beta$ aggregation as well as its interactions with aggregation inhibitors, carboxymethyldextran was used as the interaction platform [20-24].

In the present study we proposed a simple in preparation SPR biosensor based on a thioaliphatic acid self-assembled monolayer (SAM) formed on gold SPR disc. The attachment of A $\beta_{40}$ peptide probe to the carboxyl-terminated surface was performed via amide bond formation.

The proposed biosensor was applied for in situ monitoring of $\mathrm{A} \beta_{40}$ early aggregation stages (oligomerization) in the presence of potential aggregation inhibitors. The influence of arecoline, $\alpha$-lobeline, trigonelline and pseudopelletierine (Figure 1(B)) on $A \beta_{40}$ aggregation was examined. These compounds derived from domestic plants are either commonly used as psychoactive substances (arecoline and $\alpha$-lobeline) or are consumed as a dietary component (trigonelline and pseudopelletierine). Plants and products containing the considered alkaloids are easily available, which creates the possibility of using them (or their derivatives) as a diet supplementation in AD prevention and treatment. For comparison, one pharmacologically unrelated compound, pyridoxine (vitamin $\mathrm{B}_{6}$ ) was tested too. 
Figure 1. Amyloid $\beta$ peptide (1-40) amino acid sequence (A) and chemical structure of tested compounds $(\mathbf{B})$.

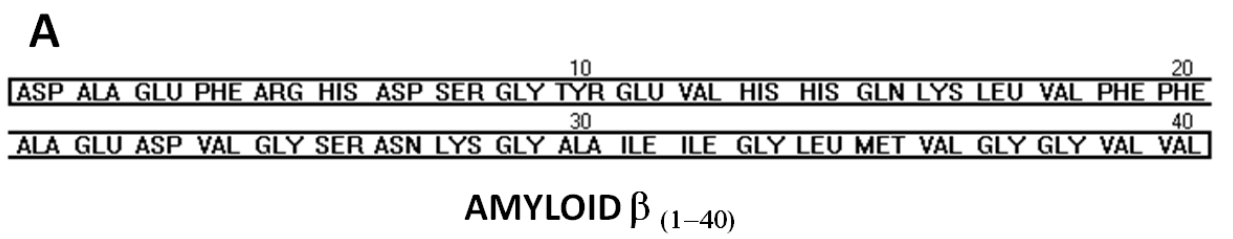

B

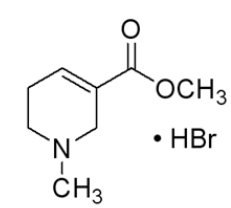

ARECOLINE

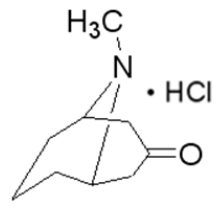

PSEUDOPELLETIERINE<smiles>C[n+]1cccc(C(=O)O)c1</smiles>

TRIGONELLINE

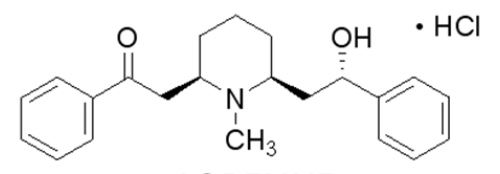

$\alpha$-LOBELINE

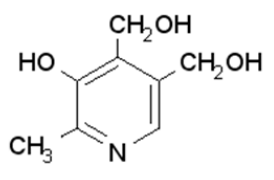

PYRIDOXINE

\section{Experimental Section}

\subsection{Chemicals}

Amyloid $\beta$ protein (1-40), trifluoroacetate salt $A \beta_{40}$ was purchased from Bachem, Switzerland (lot 1020370). Ammonium hydroxide, 11-mercaptoundecanoic acid (11-MUA), trifluoroacetic acid, 2-morpholinoethanesulfonic acid (MES), $N$-hydroxysuccinimide (NHS), $N$-(3-dimethylaminopropyl)$N$ '-ethylcarbodiimide hydrochloride (EDC), ethanolamine, pyridoxine, arecoline hydrobromide, pseudopelletierine hydrochloride, trigonelline hydrochloride, $\alpha$-lobeline hydrochloride and PBS components: sodium chloride, potassium chloride, sodium phosphate dibasic, potassium phosphate monobasic were supplied by Sigma-Aldrich, Poznań, Poland. Ethanol absolute, hydrochloric acid and sodium hydroxide were obtained from $\mathrm{POCH}$, Poland. Reagents and solvents were of analytical grade and used without any purification step. All aqueous solutions were prepared using autoclaved Milli-Q water, resistivity $18.2 \mathrm{M} \Omega \cdot \mathrm{cm}$ (Millipore Corporation, USA). All buffers used for SPR experiments were rigorously filtrated through $0.22 \mu \mathrm{m}$ sterile PVDF filters (Roth, Germany).

\subsection{Surface Plasmon Resonance Apparatus}

An Autolab Springle SPR system (Eco Chemie, The Netherlands) equipped with a thermostatic water bath (Julabo Labortechnik, Germany) was used. Springle SPR was employed for monitoring both $A \beta_{40}$ probe immobilization and $A \beta_{40}$ aggregation. The experiments were carried out continuously and the immobilization step was followed by aggregation procedure, as described below. 


\subsection{Peptide Preparation}

The lyophilized synthetic $\mathrm{A} \beta_{40}$ peptides were dissolved in $0.02 \%$ ammonia solution at the concentration of $300 \mu \mathrm{M}$ by brief vortexing. Then the solution was sonicated for $2 \mathrm{~min}$ in a water bath at $4{ }^{\circ} \mathrm{C}$. The $\mathrm{A} \beta_{40}$ aliquots were stored in at $-85^{\circ} \mathrm{C}$.

\subsection{Formation of 11-MUA SAM}

Gold-coated SPR discs were supplied by Eco Chemie, The Netherlands. Prior to modification, discs were rinsed with Milli-Q water then with ethanol and dried thoroughly in a stream of nitrogen. Gold discs were treated with UV-ozone chamber (Novascan, USA) for $20 \mathrm{~min}$ in order to remove any organic contaminations. Clean gold SPR discs were immediately immersed for $30 \mathrm{~min}$ in $1.0 \mathrm{mM}$ solution of 11-MUA in ethanol containing $2 \%$ of trifluoroacetic acid. Afterwards discs were rinsed with ethanol, $10 \%$ solution of ammonia in ethanol, again with ethanol and gently dried in a stream of nitrogen before placing in SPR chamber. Formation of 11-MUA SAM was carried out according to modified method described by Wang et al. [25].

\subsection{Immobilization $A \beta_{40}$ Peptide Probe}

Probe immobilization was performed at $22{ }^{\circ} \mathrm{C}$ using $50 \mathrm{mM}$ MES (pH 5.5) as running buffer. Freshly 11-MUA-modified discs were placed in the SPR chamber and conditioned in running buffer for $2 \mathrm{~h}$. Every $30 \mathrm{~min}$ discs were washed with $4 \mathrm{~mL}$ of running buffer. After conditioning, when stable readout was achieved, the carboxyl groups of 11-MUA SAM were activated by treating with a mixture of $100 \mathrm{mM}$ EDC and $50 \mathrm{mM}$ NHS in $50 \mathrm{mM}$ MES (pH 5.5) for $15 \mathrm{~min}$. Subsequently discs were washed with $2 \mathrm{~mL}$ of running buffer and the value of SPR angle shift was recorded after 3 min. A $\beta_{40}$ aliquots were diluted with $50 \mathrm{mM}$ MES ( $\mathrm{pH} 6.5$ ) to $30 \mu \mathrm{M}$, briefly vortexed and injected on the activated disc surface. After 20-min incubation peptide solution was rinsed off with $2 \mathrm{~mL}$ of running buffer and followed by quenching the remaining NHS-activated sites with $1.0 \mathrm{M}$ ethanolamine in $50 \mathrm{mM}$ MES (pH 8.5) for $10 \mathrm{~min}$. Finally, discs were rinsed with $4 \mathrm{~mL}$ of the running buffer and the value of SPR angle shift was recorded $10 \mathrm{~min}$ after the end wash.

\subsection{A $\beta_{40}$ Aggregations}

Aggregation experiments were performed at $37^{\circ} \mathrm{C}$ using $10 \mathrm{mM}$ PBS (pH 7.4) as running buffer. Prior to the experiment, discs with immobilized probe were washed with $4 \mathrm{~mL}$ of running buffer and conditioned until the stable readout was gained. SPR angle shift values were recorded after $1 \mathrm{~h}$ of conditioning. $\mathrm{A} \beta_{40}$ aliquots were diluted within PBS to $30 \mu \mathrm{M} .1 .0 \mathrm{mM}$ alkaloids: arecoline, pseudopelletierine, trigonelline and $\alpha$-lobeline as well as pyridoxine were dissolved in PBS. Final $\mathrm{pH}$ was adjusted to $7.4 \pm 0.05$. Then discs were incubated in a solution of $A \beta_{40}$ with a supplementation of selected alkaloid for $2 \mathrm{~h}$ followed by washing with $4 \mathrm{~mL}$ of running buffer. The same experiment, but without tested compounds has been preformed too (control aggregation). Values of SPR shift angle were recorded $20 \mathrm{~min}$ after the end wash. 
2.7. Aggregation of $A \beta_{40}$ Peptide on the Surface of 11-MUA SAM Treated with Ethanolamine after Activation with EDC/NHS (Background Aggregation)

Freshly 11-MUA-modified discs were placed in SPR chamber and conditioned in $50 \mathrm{mM}$ MES (pH 5.5) running buffer for $2 \mathrm{~h}$. Every 30 min discs were washed with $4 \mathrm{~mL}$ of running buffer. After conditioning, when stable readout was achieved, the carboxyl groups of 11-MUA SAM were activated by treating with a mixture of $100 \mathrm{mM}$ EDC and $50 \mathrm{mM}$ NHS in $50 \mathrm{mM}$ MES (pH 5.5) for $15 \mathrm{~min}$. Subsequently discs were washed with $2 \mathrm{~mL}$ of running buffer and the value of SPR angle shift was recorded after 3 min. Instead of diluted $A \beta_{40}$ peptide, a solution containing $50 \mathrm{mM}$ MES (pH 5.5) with $0.002 \%$ ammonia only was injected, incubated for 20 -min and rinsed off with $2 \mathrm{~mL}$ of running buffer. This was followed by quenching the remaining NHS-activated sites with $1.0 \mathrm{M}$ ethanolamine in $50 \mathrm{mM}$ MES ( $\mathrm{pH} \mathrm{8.5)} \mathrm{for} 10 \mathrm{~min}$. Finally, discs were rinsed with $4 \mathrm{ml}$ of the running buffer and the value of SPR angle shift was recorded $10 \mathrm{~min}$ after the end wash. Aggregation was performed at $37{ }^{\circ} \mathrm{C}$ using $10 \mathrm{mM}$ PBS (pH 7.4) as running buffer. Prior to the experiment, discs were washed with $4 \mathrm{~mL}$ of running buffer and conditioned until the stable readout was gained. SPR angle shift values were recorded after $1 \mathrm{~h}$ of conditioning. Then discs were incubated in a solution of $30 \mu \mathrm{M} A \beta_{40}$ in PBS for $2 \mathrm{~h}$ followed by washing with $4 \mathrm{~mL}$ of running buffer. Values of SPR shift angle were recorded 20 min after the end wash.

\subsection{Influence of Tested Alkaloids on SPR Angle Shift of A $\beta_{40}$-Funcionalized Disc.}

Experiments were performed at $37^{\circ} \mathrm{C}$ using $10 \mathrm{mM}$ PBS (pH 7.4) as running buffer. Prior to the experiment, discs with immobilized probe were washed with $4 \mathrm{~mL}$ of running buffer and conditioned until the stable readout was gained. SPR angle shift values were recorded after $1 \mathrm{~h}$ of conditioning. $1.0 \mathrm{mM}$ alkaloids: arecoline, pseudopelletierine, trigonelline and $\alpha$-lobeline as well as pyridoxine were dissolved in PBS containing $0.002 \%$ ammonia solution. Final pH was adjusted to $7.4 \pm 0.05$. Then discs were incubated in alkaloid solution for $2 \mathrm{~h}$ followed by washing with $4 \mathrm{~mL}$ of running buffer. Values of SPR shift angle were recorded $20 \mathrm{~min}$ after the end wash.

\subsection{Data Presentation and Statistical Analysis}

Aggregation assay results were presented as means \pm standard deviation for at least five replicates for each experimental group. Results were submitted to the t-test (The Analysis ToolPak, Microsoft, USA) and values of $p<0.05$ were considered as statistically significant.

\section{Results and Discussion}

The 11-MUA-modified SPR gold discs were utilized for the covalent binding of $A \beta_{40}$ peptide probe. The immobilization procedure scheme is shown in Figure 2. The immobilization of $A \beta_{40}$ peptide probe, performed via EDC/NHS coupling chemistry [26], was monitored constantly and the SPR angle shift was recorded. The representative binding curve was illustrated in Figure 3. The probe-immobilizing procedure resulted in around $0.55 \pm 0.12 \mathrm{ng}$ of $\mathrm{A} \beta_{40}$ peptide attached per $1 \mathrm{~mm}^{2}$ of disc surface. 
Figure 2. Scheme of $A \beta_{40}$ probe immobilization on 11-MUA-modified surface of SPR gold disc $(\mathbf{A}-\mathbf{C})$ and $A \beta_{40}$ aggregation assay on $A \beta_{40}$-functionalized gold discs surface (D-E).

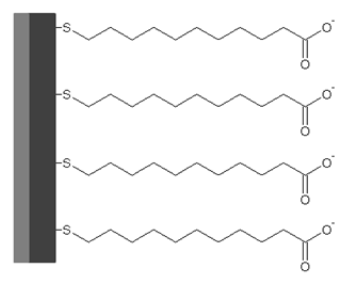

A. 11-MUA SAM

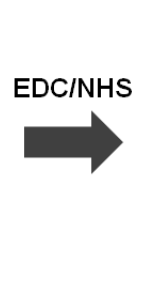
11-MUA SAM

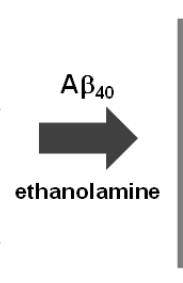

C. $A \beta_{40}$-immobilized 11-MUA SAM

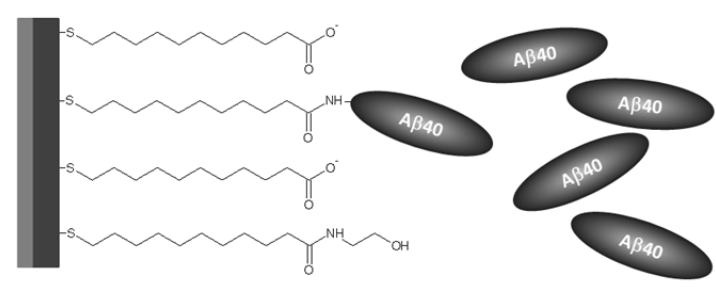

D. Surface-bound $A \beta_{40}$ probe incubated with fresh $A \beta_{40}$ solution

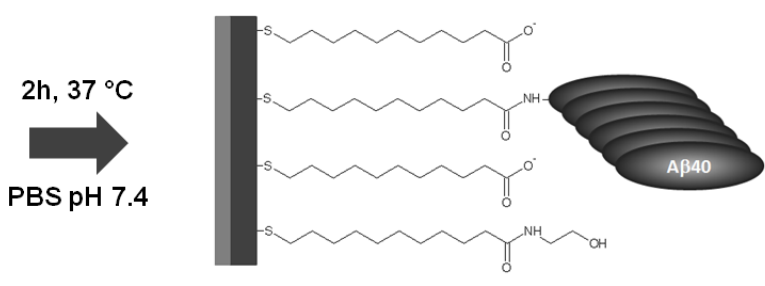

E. $A \beta_{40}$ aggregation

Figure 3. SPR binding curve for $A \beta_{40}$ immobilization on 11-MUA-SAM modified gold disc (For measurement details, see Experimental part 2.5).

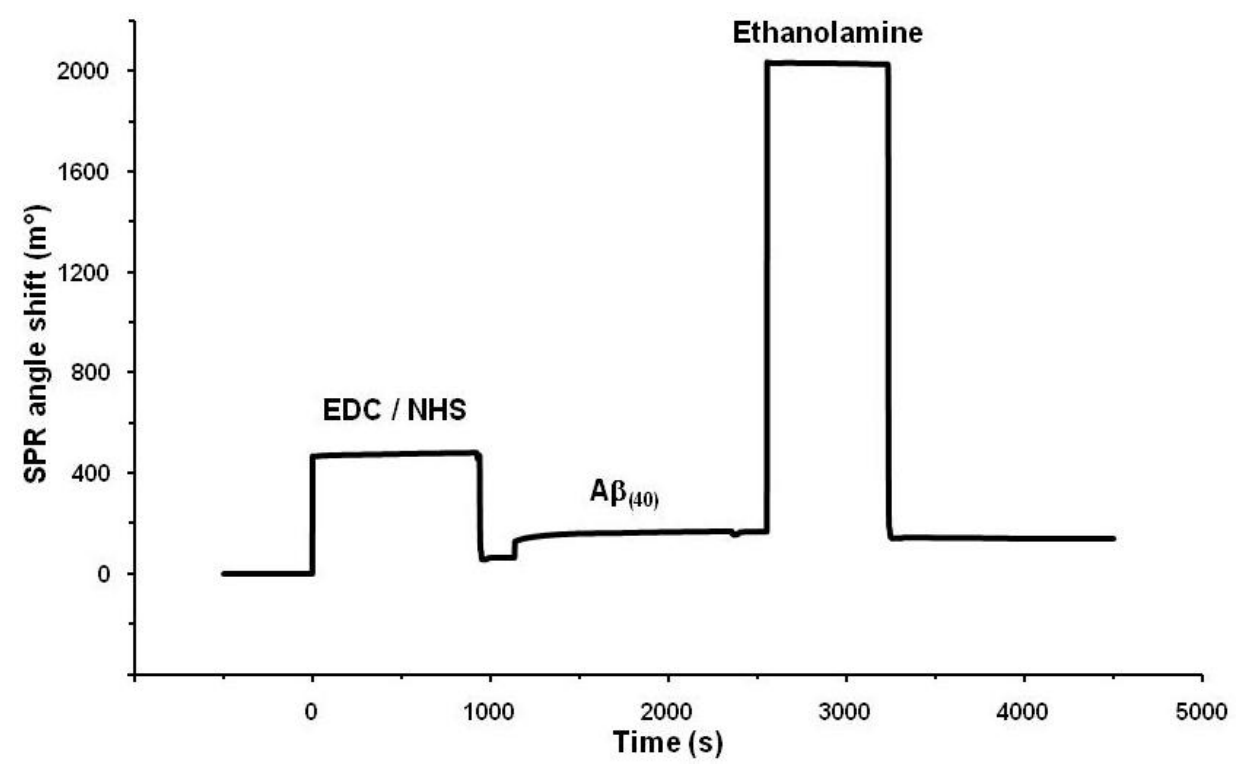

In order to check if the proposed biosensor is able to detect the early steps of the aggregation process, two series of control aggregations were carried out. In first, the $A \beta_{40}$ solution was injected on the surface of $A \beta_{40}$ functionalized disc (control aggregation), and in second, the same solution was injected on the disk surface modified only with 11-MUA SAM, which was treated with ethanolamine after activation with EDC/NHS (background aggregation). The value of SPR angle shifts for control aggregation was $125.7 \pm 15.6 \mathrm{~m}^{\circ}$ and for background only $60.1 \pm 3.6 \mathrm{~m}^{\circ}$ (Figure 4(A)). This indicated that the rate of specific deposition of $A \beta_{40}$ on surface modified with $A \beta_{40}$-probe was $c a$. $50 \%$ higher 
than non-specific background deposition of $\mathrm{A} \beta_{40}$ on the ethanolamine deactivated 11-MUA SAM. The phenomenon of beta-amyloid aggregation on the surface of SAMs with different functional groups (without $A \beta_{40}$-probe) was reported in the literature [27]. The authors concluded that SAMs induced aggregation of $A \beta$. The hybrophobicity /hydrophilicy of functional groups present on the SAMs' surface is the main factor which governs this phenomenon. Molecular docking and dynamics simulations have been applied for exploring the conformational changes and adsorption behaviour of $\mathrm{A} \beta$ monomer on various SAMs. The hydrophobic $\mathrm{CH}_{3}$-SAM has a lower energy barrier for $\mathrm{A} \beta$ monomer adsorption than OH-SAM [28]. For the $\mathrm{COOH}-\mathrm{SAM}$ and $\mathrm{NH}_{2}$-SAM bearing relatively large charge in the head groups, electrostatic interactions between $\mathrm{A} \beta$ and SAMs provide the additional driving force for $A \beta$ adsorption [29]. The background $A \beta$ aggregation was performed on the 11-MUA SAM, treated with ethanolamine after activation with EDC/NHS. Thus, on this surface the OH groups are dominant. Only a few $\mathrm{COOH}$ could be present, so A $\beta$ monomer adsorption on such SAM is driven by very weak A $\beta$-SAM interactions with strong SAM-water interactions which results in a net weak affinity of A $\beta$ adsorption on OH-SAM [29]. Prior to aggregation assays with alkaloids and pyridoxine, possible interactions between those compounds and the $A \beta_{40}$-functionalized SPR gold disc were checked. Incubations of probe-modified discs with the tested alkaloids injected alone onto disc surface revealed that SPR angle shifts were negligible $\left(-0.8 \mathrm{~m}^{\circ}\right.$ for arecoline, $-0.6 \mathrm{~m}^{\circ}$ for $\alpha$-lobeline, $0.5 \mathrm{~m}^{\circ}$ for pseudopelletierine, $-0.3 \mathrm{~m}^{\circ}$ for trigonelline and $0.5 \mathrm{~m}^{\circ}$ for pyridoxine). Thus, the proposed assay was deemed selective and suitable for performing the $A \beta_{40}$ aggregation processes in the presence of selected compounds.

Figure 4(B-E) shows the representative binding curves for incubation of $A \beta_{40}$-probe-functionalized gold discs with $A \beta_{40}$ solution containing $1.0 \mathrm{mM}$ of tested alkaloid. For comparison the representative binding curve for incubation of $A \beta_{40}$-probe-functionalized disc with $A \beta_{40}$ solution without any additives (control aggregation) was included.

Figure 4. The representative SPR binding curves for $A \beta_{40}$ aggregations. (A) Aggregations of $A \beta_{40}$ injected alone performed on SPR gold discs surface functionalized with: $A \beta_{40}$ probe (control) or with 11-MUA SAM treated with ethanolamine after activation with EDC/NHS (background); (B-F) Aggregations of $A \beta_{40}$ injected alone (control) or in the presence of $1.0 \mathrm{mM}$ of tested compound performed on a $\mathrm{A} \beta_{40}$-functionalized gold discs surface (For measurement conditions-see Experimental parts: 2.6 and 2.7).
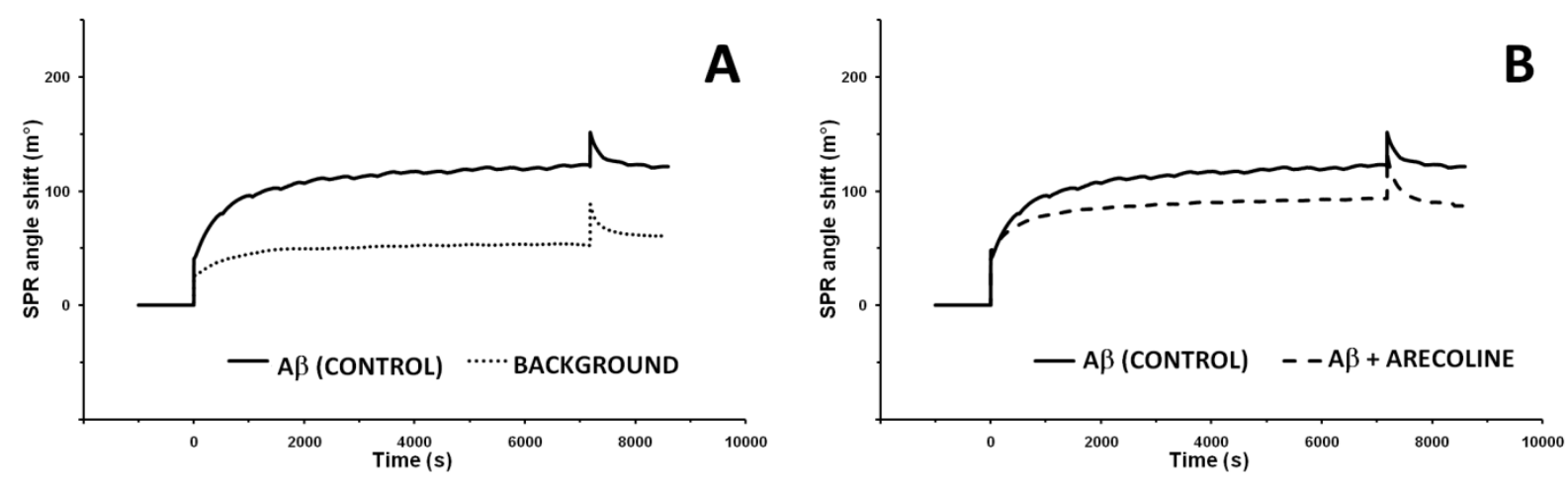
Figure 4. Cont.
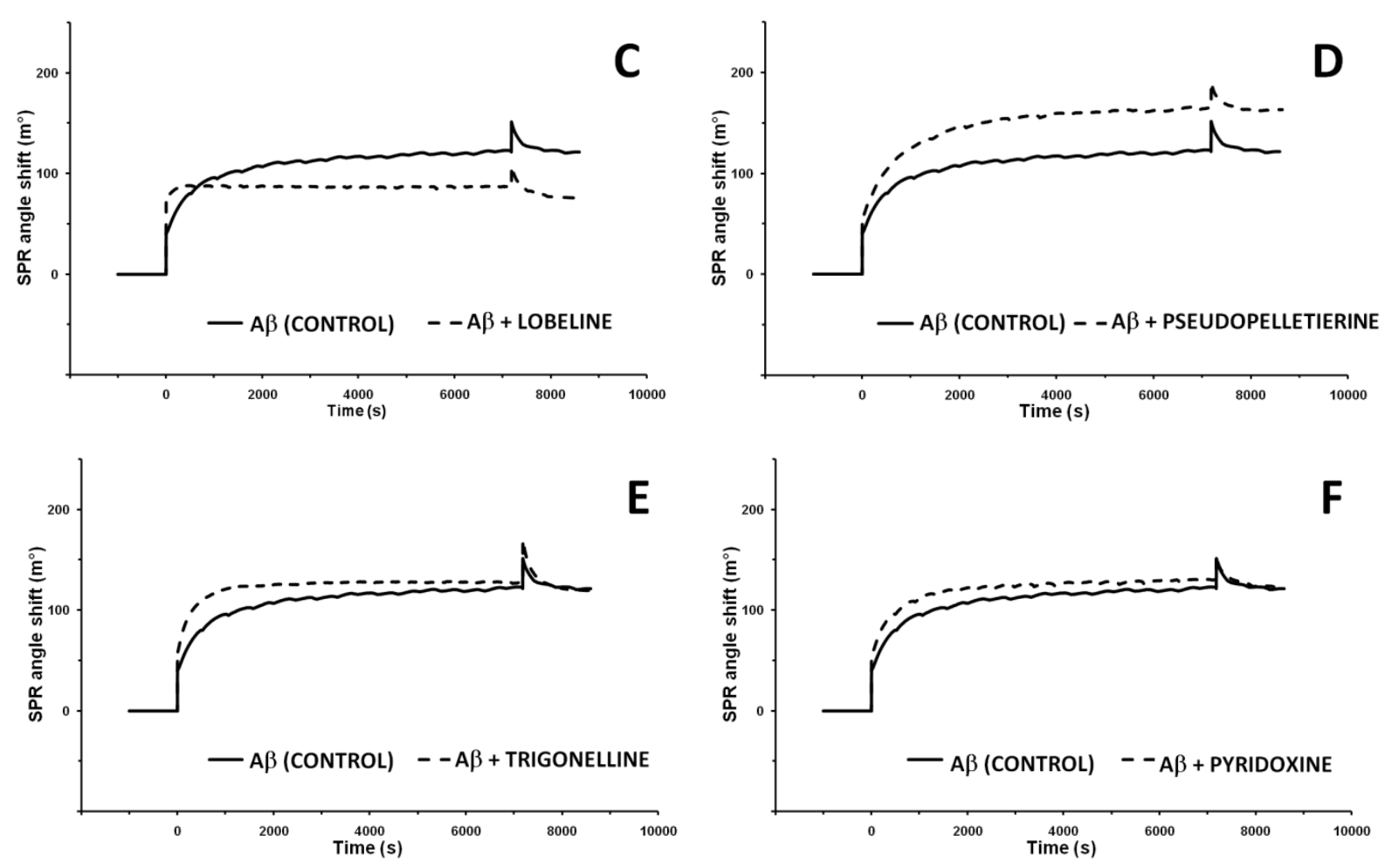

The addition of $\alpha$-lobeline and arecoline to the assay significantly $(p<0.01)$ decreased $A \beta_{40}$ aggregation. Values of SPR angle shifts decreased from $125.7 \pm 15.6 \mathrm{~m}^{\circ}$ for control incubation (A $\beta_{40}$ injected alone) to $83.1 \pm 16.5 \mathrm{~m}^{\circ}$ for arecoline (Figure $4(\mathrm{~B})$ ) and $74.8 \pm 23.8 \mathrm{~m}^{\circ}$ for $\alpha$-lobeline supplementation (Figure $4(\mathrm{C})$ ). On the contrary, addition of pseudopelletierine to the aggregation assay showed a tendency to elevate SPR angle shift to $164.5 \pm 14.1 \mathrm{~m}^{\circ}$ (Figure 4(D)). Trigonelline did not affect $A \beta_{40}$ peptide deposition and SPR angle shift resulted in $121.9 \pm 25.6 \mathrm{~m}^{\circ}$ (Figure 4(E)). Aggregation assay with addition of pharmaceutically unrelated compound, pyridoxine (vitamin $\mathrm{B}_{6}$ ), did not influence $A \beta_{40}$ deposition (122.5 $\pm 14.4 \mathrm{~m}^{\circ}$; Figure $\left.4(\mathrm{~F})\right)$.

Figure 5. SPR angle shift values for $A \beta_{40}$ aggregation on an $A \beta_{40}$-functionalized gold discs. Measurement conditions: see Experimental part 2.6; values are significantly different $(\mathrm{P}<0.01) ; \mathrm{N}=5$.

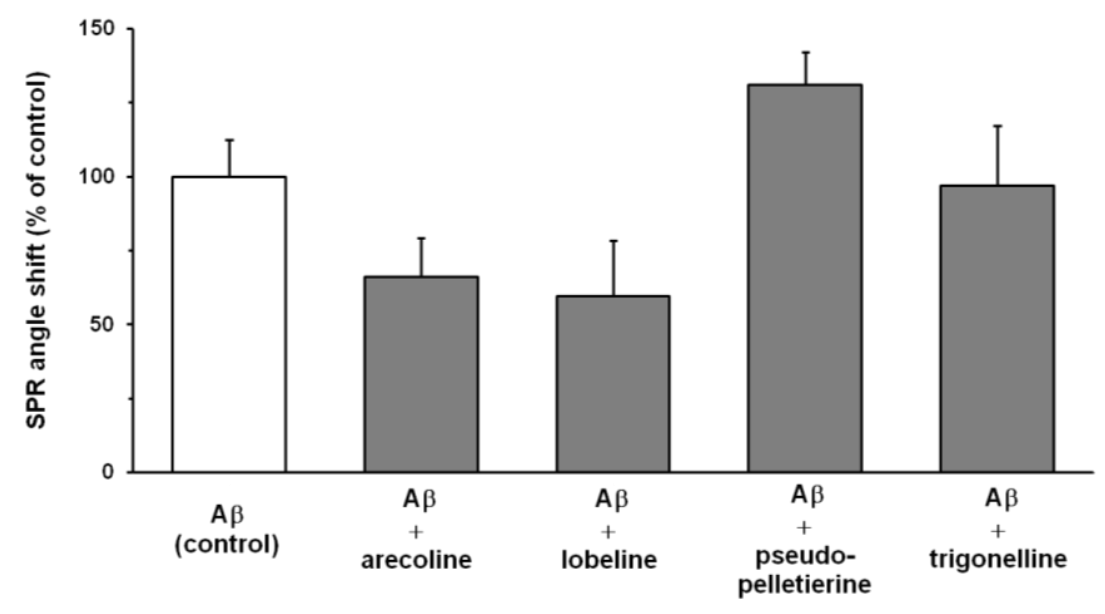


The values of SPR angle shift was recorded 20 min after the final wash. A $\beta_{40}$ deposition obtained for incubations with tested compounds was calculated relative to the aggregation control (100\%) (Figure 5).

In our previous study, association constants for $A \beta_{40}$ peptide and selected alkaloids were established electrochemically [16]. The highest affinity to the $A \beta_{40}$ was determined for arecoline: $2.30 \times 10^{8} \mathrm{M}^{-1}$. The association constant for $\alpha$-lobeline was equal to $0.90 \times 10^{8} \mathrm{M}^{-1}$, while binding of pseudopelletierine $\left(0.57 \times 10^{8} \mathrm{M}^{-1}\right)$ and trigonelline $\left(0.28 \times 10^{8} \mathrm{M}^{-1}\right)$ were relatively weaker [16]. In the present study, only two alkaloids: $\alpha$-lobeline and arecoline, were shown to be potential inhibitors of early $A \beta_{40}$ aggregation and their therapeutic and/or prophylactic significance can be suggested.

The phenomenon of interaction between examined compounds and $\mathrm{A} \beta$ peptide, resulting in altered aggregation, can be considered as a process composed of two steps. At the first stage alkaloid passes through the water-peptide interface, moving from aqueous phase to the relatively lipophilic environment consisted of $A \beta$ molecules, either deposited on gold disc surface or remaining in the solution. In that case the permeability of substance is determined by its lipophilicity. This attribute also governs drug bioavailability and cannot be neglected when potential therapeutic or prophylactic benefits of compound administration are considered. Thus, the lipophilicity of drug candidate is an important factor which enables any subsequent ligand-A $\beta_{40}$ peptide interactions. The second step of considered phenomenon refers to the direct interaction between the drug-and receptor site in the peptide. These two factors, ability to cross the interface and binding to the specific fragment of the peptide can be crucial for determining the effects of alkaloid influence on $A \beta_{40}$ aggregation observed herein.

In light of those assumptions, the lipophilicity of tested compounds was taken into account. Log D $(\mathrm{pH}$ 7.4) values of the examined alkaloids and pyridoxine were found in ChemSpider online database [30] and was collected in Table $1 . \log \mathrm{D}$ is an octanol/water partition coefficient, where the neutral species as well as ionized forms are considered. It is assumed to be accurate for the prediction of molecule hydrophilic or lipophilic behaviour under given $\mathrm{pH}$ [31]. The theoretical $\log \mathrm{D}$ values revealed that arecoline and $\alpha$-lobeline are the most lipophilic among the studied alkaloids. Their $\log \mathrm{D}$ values are equal to 0.71 and 2.14 respectively. Both of them appear to be inhibitors of $A \beta_{40}$ aggregation.

Table 1. $\mathrm{A} \beta_{40}$ aggregation in relation to control (100\%), $\log D(\mathrm{pH} 7.4)$ values of alkaloids [30] and their association constants with $A \beta_{40}$ peptide [16].

\begin{tabular}{cccc}
\hline Compound & $\begin{array}{c}\text { Aggregation } \\
\text { [\%]of control }\end{array}$ & $\begin{array}{c}\text { Log D } \\
\text { pH 7.4 }[\mathbf{3 0}]\end{array}$ & $\begin{array}{c}\mathbf{L o g}_{\mathbf{a}} \\
\mathbf{1 0}^{\mathbf{8}}\left[\mathbf{M}^{-\mathbf{1}}\right][\mathbf{1 6}]\end{array}$ \\
\hline Lobeline & $59.1 \pm 18.9$ & 2.14 & 0.90 \\
Arecoline & $66.1 \pm 13.1$ & 0.71 & 2.30 \\
Pseudopelletierine & $130.9 \pm 11.2$ & -0.96 & 0.57 \\
Trigonelline & $97.0 \pm 20.4$ & -3.31 & 0.28 \\
Pyridoxine & $97.5 \pm 11.4$ & -1.45 & - \\
\hline
\end{tabular}

The $\log \mathrm{D}$ values of pseudopelletierine and trigonelline are -0.96 and -3.31 , respectively, showing the predominantly hydrophilic character of these compounds under physiological $\mathrm{pH}$. Pseudopelletierine demonstrated similar affinity towards $A \beta_{40}$ peptide as was recorded for trigonelline 
or $\alpha$-lobeline [16], but at the same time, this compound induced an acceleration of the $A \beta_{40}$ aggregation process. The specific non-flat geometry of pseudopelletierine molecule (Figure 1) could be responsible for the observed effect. The results we have got for trigonelline indicated that the hydrophilicity of this compounds is a decisive parameter governing its very weak interaction with $\mathrm{A} \beta_{40}$ peptide. Similar results were observed for pyridoxine (vitamin $B_{6} ; \log D=-1.45$ ) which is known as a neutral compound concerning $\mathrm{A} \beta_{40}$ peptide aggregation.

Protein aggregation processes have been widely explored by fluorescence assays [14,21,23,32], circular dichroism spectroscopy [11,22], atomic force microscopy [21,23,27,33] electrochemical methods [15,16,34] as well as SPR based biosensors [19-24,26,35-37]. The development of SPR techniques improved crucially the performance of bio-chemical sensing devices [38-40].

Here, we present the simple thioaliphatic carboxylic acid monolayer deposited in the one step of modification on the surface of SPR gold disc. Such a simple modification was suitable for covalent attaching of $A \beta_{40}$-peptide probe via amide bond formation. It is worth underlining that the surface of 11-MUA SAM displayed good selectivity. The unspecific aggregation of $A \beta_{40}$ was significantly lower in the comparison to the $A \beta_{40}$ aggregation performed on the surface with $A \beta_{40}$ probe covalently bound via amide bonds (Figure 4(A)).

\section{Conclusions}

The proposed SPR biosensor based on 11-mercaptoundecanoic acid (11-MUA) was useful for study of the influence of several alkaloids - arecoline hydrobromide, pseudopelletierine hydrochloride, trigonelline hydrochloride, $\alpha$-lobeline hydrochloride — on the aggregation process of $A \beta_{40}$-peptide. The measurement system was selective. Pyridoxine (vitamin $\mathrm{B}_{6}$ ), which is known as a neutral compound for $A \beta_{40}$-peptide aggregation, displayed no influence on this phenomenon when studied by the analytical tool proposed. The obtained results showed that developed SPR-based biosensors could be applied for monitoring of $A \beta_{40}$ aggregation phenomena in real-time, without using any chemical markers influencing the process.

\section{Acknowledgements}

Presented work was supported by the Polish Ministry of Science and Higher Education-Grant POL-POSTDOC III PBZ/MNiSW/07/2006/60 and Institute of Animal Reproduction and Food Research of Polish Academy of Science, Olsztyn, Poland.

\section{References}

1. Koo, E.H.; Lansbury, P.T.; Kelly, J.W. Amyloid diseases: Abnormal protein aggregation in neurodegeneration. Proc. Natl. Acad. Sci. USA 1999, 96, 9989-9990.

2. Hardy, J.; Selkoe, D.J. The amyloid hypothesis of Alzheimer's disease: Progress and problems on the road to therapeutics. Science 2002, 297, 353-356.

3. Murphy, M.P.; LeVine, H., III. Alzheimer's disease and the amyloid-beta peptide. J. Alzheimers Dis. 2010, 19, 311-323. 
4. Morgan, C.; Colombres, M.; Nuñez, M.T.; Inestrosa, N.C. Structure and function of amyloid in Alzheimer's disease. Prog. Neurobiol. 2004, 74, 323-349.

5. Gsponer, J.; Vendruscolo, M. Theoretical approaches to protein aggregation. Protein Pept. Lett. 2006, 13, 287-293.

6. Wang, H.W.; Pasternak, J.F.; Kuo, H.; Ristic, H.; Lambert, M.P.; Chromy, B.; Viola, K.L.; Klein, W.L.; Stine, W.B.; Krafft, G.A.; Trommer, B.L. Soluble oligomers of beta amyloid (1-42) inhibit long-term potentiation but not long-term depression in rat dentate gyrus. Brain Res. 2002, 924, 133-140.

7. Levin, E.D.; McClernon, F.J.; Rezvani, A.H. Nicotinic effects on cognitive function: Behavioural characterization, pharmacological specification, and anatomic localization. Psychopharmacology (Berlin) 2006, 184, 523-539.

8. Emilien, G.; Beyreuther, K.; Masters, C.L.; Maloteaux, J.M. Prospects for pharmacological intervention in Alzheimer disease. Arch Neurol. 2000, 57, 454-459.

9. Zamani, M.R.; Allen, Y.S. Nicotine and its interaction with beta-amyloid protein: A short review. Biol. Psychiatry 2001, 49, 221-232.

10. Pogocki, D.; Ruman, T.; Danilczuk, M.; Celuch, M.; Wałajtys-Rode, E. Application of nicotine enantiomers, derivatives and analogues in therapy of neurodegenerative disorders. Eur. J. Pharmacol. 2007, 563, 18-39.

11. Salomon, A.R.; Marcinowski, K.J.; Friedland, R.P.; Zagorski, M.G. Nicotine inhibits amyloid formation by the beta-peptide. Biochemistry 1996, 35, 13568-13578.

12. Zeng, H.; Zhang, Y.; Peng, L.; Shao, H.; Menon, N.K.; Yang, J.; Salomon, A.R.; Freidland, R.P.; Zagorski, M.G. Nicotine and amyloid formation. Biol. Psychiatry 2001, 49, 248-257.

13. Moore, S.A.; Huckerby, T.N.; Gibson, G.L.; Fullwood, N.J.; Turnbull, S.; Tabner, B.J.; El-Agnaf, O.M.; Allsop, D. Both the D-(+) and L-(-) enantiomers of nicotine inhibit Abeta aggregation and cytotoxicity. Biochemistry 2004, 43, 819-826.

14. Ono, K.; Hasegawa, K.; Yamada, M.; Naiki, H. Nicotine breaks down preformed Alzheimer's beta-amyloid fibrils in vitro. Biol. Psychiatry 2002, 52, 880-886.

15. Szymańska, I.; Radecka, H.; Radecki, J.; Kaliszan, R. Electrochemical impedance spectroscopy for study of amyloid beta-peptide interactions with (-) nicotine ditartrate and (-) cotinine. Biosens. Bioelectron. 2007, 22, 1955-1960.

16. Grabowska, I.; Radecka, H.; Burza, A.; Radecki, J.; Kaliszan, M.; Kaliszan, R. Association constants of pyridine and piperidine alkaloids to amyloid beta peptide determined by electrochemical impedance spectroscopy. Curr. Alzheimer Res. 2010, 7, 165-172.

17. White, D.A.; Buell, A.K.; Dobson, C.M.; Welland, M.E.; Knowles T.P. Biosensor-based label-free assays of amyloid growth. FEBS Lett. 2009, 583, 2587-2592.

18. Aguilar, M.I.; Small, D.H. Surface plasmon resonance for the analysis of beta-amyloid interactions and fibril formation in Alzheimer's disease research. Neurotox. Res. 2005, 7, 17-27.

19. Hu, W.P.; Chang, G.L.; Chen, S.J.; Kuo, Y.M. Kinetic analysis of beta-amyloid peptide aggregation induced by metal ions based on surface plasmon resonance biosensing. J. Neurosci. Meth. 2006, 154, 190-197.

20. Cairo, C.W.; Strzelec, A.; Murphy, R.M.; Kiessling, L.L. Affinity-based inhibition of beta-amyloid toxicity. Biochemistry 2002, 41, 8620-8629. 
21. Liu, R.; Yuan, B.; Emadi, S.; Zameer, A.; Schulz, P.; McAllister, C.; Lyubchenko, Y.; Goud, G.; Sierks, M.R. Single chain variable fragments against beta-amyloid (Abeta) can inhibit Abeta aggregation and prevent abeta-induced neurotoxicity. Biochemistry 2004, 43, 6959-6967.

22. Lindgren, J.; Wahlström, A.; Danielsson, J.; Markova, N.; Ekblad, C.; Gräslund, A.; Abrahmsén, L.; Karlström, A.E.; Wärmländer, S.K. N-terminal engineering of amyloid- $\beta$-binding affibody molecules yields improved chemical synthesis and higher binding affinity. Protein Sci. 2010, 19, 2319-2329.

23. Hirohata, M.; Hasegawa, K.; Tsutsumi-Yasuhara, S.; Ohhashi, Y.; Ookoshi, T.; Ono, K.; Yamada, M.; Naiki, H. The anti-amyloidogenic effect is exerted against Alzheimer's beta-amyloid fibrils in vitro by preferential and reversible binding of flavonoids to the amyloid fibril structure. Biochemistry 2007, 46, 1888-1899.

24. Ryu, J.; Joung, H.A.; Kim, M.G.; Park, C.B. Surface plasmon resonance analysis of Alzheimer's beta-amyloid aggregation on a solid surface: from monomers to fully-grown fibrils. Anal Chem. 2008, 80, 2400-2407.

25. Wang, H.; Chen, S.; Li, L.; Jiang, S. Improved method for the preparation of carboxylic acid and amine terminated self-assembled monolayers of alkanethiolates. Langmuir 2005, 21, 2633-2636.

26. Cannon, M.J.; Williams, A.D.; Wetzel, R.; Myszka, D.G. Kinetic analysis of beta-amyloid fibril eleongation. Anal. Biochem. 2004, 328, 67-75.

27. McMasters, M.J.; Hammer, R.P.; McCarley, R.L. Surface-induced aggregation of beta amyloid peptide by $\omega$-substituted alkanethiol monolayers supported on gold. Langmuir 2005, 21, 4464-4470.

28. Wang, Q.; Zhao, C.; Zhao, J.; Wang, J.; Yang, J.-C.; Yu, X.; Zheng, J. Comparative molecular dynamics study of $A \beta$ adsorption on the self-assembled monolayers. Langmuir 2010, 26, 3308-3316.

29. Wang, Q.; Zhao, J.; Yu, X.; Zhao, C.; Li, L.; Zheng, J. Alzheimer A $\beta_{1-42}$ monomer adsorbed on the self-assembled monolayers. Langmuir 2010, 26, 12722-12732.

30. ChemSpider. Available online: http://nature.chemspider.com (accessed on 16 February 2011).

31. Bhal, S.K.; Kassam, K.; Peirson, I.G.; Pearl, G.M. The rule of five revisited: Applying log D in place of $\log \mathrm{P}$ in drug-likeness filters. Mol. Pharm. 2007, 4, 556-560.

32. Ono, K.; Hasegawa, K.; Naiki, H.; Yamada, M. Curcumin has potent anti-amyloidogenic effects for Alzheimer's $\beta$-amyloid fibrils in vitro. J. Neurosci. Res. 2004, 75, 742-750.

33. Yagi, H.; Ban, T.; Morigaki, K.; Naiki, H.; Goto, Y. Visualaization and classification of amyloid $\beta$ supramolecular assemblies. Biochemistry 2007, 46, 15009-15017.

34. Zhou, N.; Chen, Z.; Zhang, D.; Li, G. Electrochemical assay of human islet amyloid polypeptide and its aggregation. Sensors 2008, 8, 5987-5995.

35. Gobbi, M.; Re, R.; Canovi, M.; Beeg, M.; Gregori, M.; Sesana, S.; Sonnino, S.; Brogioli, D.; Musicanti, C.; Gasco, P.; Salmona, M. Lipid-base nanoparticles with high binding affinity for amyloid- beta $_{1-42}$ peptide. Biomaterials 2010, 31, 6519-6529.

36. Kremer, J.J.; Murphy, R.M. Kinetics of adsorption of Abeta(1-40) to lipid bilayers. J. Biochem. Biophys. Meth. 2003, 57, 159-169. 
37. Hasegawa, K.; Ono, K.; Yamada, M.; Naiki, H. Kinetic modeling and determination of reaction constants of Alzheimer's beta-amyloid fibril extension and disscociation using surface plasmon resonanace. Biochemistry 2002, 41, 13489-13498.

38. Rusnati, M.; Bugatti, A.; Mitola, S.; Leali, D.; Bergese, P.; Depero, L.E.; Presta, M. Exploiting surface plasmon resonance (SPR) technology for the identification of fibroblast growth factor-2 (FGF2) anatgonists endowed with antiangiogenic activity. Sensors 2009, 9, 6471-6503.

39. Roh, S.; Chung, T.; Lee, B. Overview of the characteristic of micro- and nanao-structured surface plasmon resonanace. Sensors 2011, 11, 1565-1588.

40. Lee, K.-S.; Son, J.M.; Jeong, D.-Y.; Lee, T.S.; Kim, W.M. Resolution enhacement in surface plasmon resonanace sensor based on waveguide coupled mode by combining a bimetallic approach. Sensors 2010, 10, 11390-11399.

(C) 2011 by the authors; licensee MDPI, Basel, Switzerland. This article is an open access article distributed under the terms and conditions of the Creative Commons Attribution license (http://creativecommons.org/licenses/by/3.0/). 